\title{
Practice parameters for the management of single brain metastasis
}

\author{
JaCK P. Rock, M.D., Stephen Haines, M.D., LaWrence Recht, M.D., \\ Mark Bernstein, M.D., RaYmond SaWaYa, M.D., Tom MikKelSEN, M.D., \\ AND JAY LOEFFLER, M.D.
}

\begin{abstract}
Department of Neurosurgery, Henry Ford Hospital, Detroit, Michigan; Department of Neurosurgery, Medical University of South Carolina, Charleston, South Carolina; Department of Neurology, University of Massachusetts Medical Center, Worcester, and Department of Radiation Oncology, Northeast Proton Therapy Center, Massachusetts General Hospital, Boston, Massachusetts; Toronto Hospital, Western Division, Toronto, Ontario, Canada and MD Anderson Cancer Center, Houston, Texas
\end{abstract}

\begin{abstract}
Object. In January 1998 the Guidelines and Outcomes Committee of the American Association of Neurological Surgeons (AANS) issued a charge for the development of evidence-based practice parameters focusing on the treatment of patients with single metastasis to the brain. The charge was imposed in response to the significant controversy surrounding questions relating to the optimal management strategies for patients with single brain metastasis.

Methods. A team consisting of physicians from the AANS, the American Academy of Neurology, and the American Association of Therapeutic Radiation Oncology convened and the literature was reviewed. Methodically drawing from the best of Class I, II, and III levels of available evidence, authors sought to determine how the literature addressed and disposed of the question of the optimal management for an adult with a known history of cancer and a single metastatic brain lesion. Framing the question in this specific manner allowed researchers to focus directly on treatment issues, without having to consider diagnostic issues.

Conclusions. The results of the evidence-based analysis demonstrated that there was insufficient information to establish standards of care. Data from the literature does, however, support a guideline stating that surgical resection accompanied by whole brain radiation therapy is associated with the best survival rate. Additional lower-quality evidence supports an option for management with radiosurgery.
\end{abstract}

\section{KEY WORDS - practice parameter • metastasis • treatment evaluation}

In April 1994, the Guidelines and Outcomes Committee of the AANS issued a charge to develop practice parameters for the treatment of low-grade glioma in adult patients. Research was undertaken in response to this charge and the report of resulting data was published in 1998. Subsequently, a second project was undertaken under the auspices of the AANS-Congress of Neurological Surgeons Joint Tumor Section to develop practice parameters for the treatment of adult patients with known cancer and a single metastatic brain lesion, and the results of that effort form the substance of this report.

Brain metastasis was studied because it is the most common type of intracranial tumor, with an annual incidence rate of more than 100,000 cases. The majority of

\footnotetext{
Abbreviations used in this paper: AAN = American Academy of Neurology; AANS = American Association of Neurological Surgeons; ASTRO = American Association of Therapeutic Radiation Oncology; BrdU = bromodeoxyuridine; $\mathrm{CNS}=$ central nervous system; $\mathrm{CT}=$ computerized tomography; IRS = I-125 seeds; KPS = Karnofsky Performance Scale; MR = magnetic resonance; RS = radiosurgery; RTOG = Radiation Therapy Oncology Group; $\mathrm{WBRT}=$ whole-brain radiation therapy.
}

patients with brain metastases have either multiple tumors or uncontrolled systemic disease, whereas the remainder have single lesions. Systemic disease status is the single most reliable predictor of survival. The management of the following two groups of patients with single brain metastasis has been controversial: 1) those having uncontrolled systemic disease and predictably shortened survival, but whose brain metastasis, if successfully treated, would allow for the maintenance of a satisfactory quality of life for the duration of expected survival; and 2) those having controlled systemic disease. In this study the following definitions were used: if systemic disease was undocumented, one brain lesion was referred to as a "solitary" lesion, but if systemic disease was documented, one brain lesion was referred to as a "single" lesion. Because issues of diagnosis of both systemic and metastatic diseases are so large and complex, we restricted our research to relate solely to the treatment of patients with diagnosed cancer and a known single or solitary metastastic brain lesion. We then attempted to answer the question of what is the optimal therapy for an adult ( $>18$ years of age) patient with a single metastasis to the brain from a non-CNS malignancy. 


\section{METHODS}

\section{Literature Search}

The Brain Metastasis Guidelines Team members of the AANS were invited to participate by the Guidelines and Outcomes Committee of the AANS and the AANS-CNS Joint Tumor Section and included two neurooncologists, one radiation oncologist, and four neurosurgeons. Three members of the AANS Guidelines and Outcomes Committee also joined the research team. Medline and Embase searches for the years 1966 to 1998 and 1974 to 1998 , respectively, were performed using the MeSH subject headings "surgery" or "surgical procedures," "operative" (exploded) or "craniotomy" or "radiotherapy" (exploded) plus the unattached subheadings "surgery" or "radiotherapy" or "drug therapy" or "prevention and control" or "therapy" or "radiography" or "gamma knife" plus text words "whole brain radiation therapy" as well as "stereotact" (as a root) within 3 words of "biopsy." These terms were combined with the MeSH terms "brain neoplasms" (exploded) and "neoplasm metastasis" (exploded) plus text words "brain" within 3 words of "metast" (root). The therapy terms were combined with brain metastasis terms. Then the text words "single" or "solitary" within five words of "brain" or "metast" (root) were combined with the therapy of brain metastases terms. The resulting set was limited to those articles concerning humans. A total of 318 articles on Medline and 284 articles on Embase were found. Researchers reviewed the abstracts of each of the 602 articles and selected 75 that directly related to our research. $^{1-76}$

A more complete review of the articles was based on the following criteria: original work published in the peerreviewed literature; entire manuscript available (no article was reviewed based solely on its abstract); subject matter directly or indirectly addressing the treatment of a single metastasis with surgery, various radiation therapy approaches (including standard radiation, radiosurgery, and brachytherapy), chemotherapy, or various combinations of these treatments. Complete review involved reading and abstracting the materials, methods, and results sections of each article with the aid of a standard form designed by the research team. In addition, the quality of the evidence in each article was classified according to the criteria listed in Table 1. The 75 articles were divided among team members so that at least two individuals reviewed each one. Thirty-one key articles consisted of relevant data and methods that allowed for interpretation of the results. Seven articles contained Class I evidence, ${ }^{18,39}$, 40,47-49,67 two articles had Class II evidence, ${ }^{3,56}$ and only 21 of the remaining 67 articles with Class III having evidence

TABLE 1

Classification of quality of evidence

\begin{tabular}{ll}
\hline \hline Class & \multicolumn{1}{c}{ Type of Evidence } \\
\hline Class I & $\begin{array}{l}\text { well-designed randomized controlled clinical trials } \\
\text { well-designed nonrandomized controlled studies such as } \\
\text { Class II }\end{array}$ \\
Class III & $\begin{array}{c}\text { expert opinion, nonrandomized historical controls, case } \\
\text { series, or case reports }\end{array}$ \\
\hline
\end{tabular}

provided relevant data. ${ }^{4,6,12-15,23,31,34,36,38,44,46,54,55,59,60,68,72,76}$ Although many of the other articles with Class III evidence provided similar or sometimes unique information, team members concluded that it was not possible from a methodological standpoint to reliably abstract pertinent data from these studies. Therefore, based on these 26 reports, practice parameters were generated.

The following definitions were considered in forming these practice parameters. ${ }^{16}$ Standards are generally accepted principles for patient management, which reflect a high degree of clinical certainty (based on Class I evidence or, when circumstances preclude randomized controlled clinical trials, overwhelming evidence from either Class II studies that directly address the question at hand or a decision analysis that directly addresses all the issues). Guidelines are recommendations for patient management that may identify a particular strategy or range of strategies and reflect moderate clinical certainty (based on Class II evidence or a decision analysis that directly addresses the issue or on strong consensus of Class III evidence). Practice options or advisories include other patient management strategies for which there is unclear clinical certainty (based on inconclusive or conflicting evidence or opinion).

\section{Therapeutic Modality and End Point Selection}

Although the end points with which to evaluate the effectiveness of treatment have not been definitively established, we judged efficacy according to the following criteria: 1) local control of the single metastasis; 2) prevention of the development of further CNS disease (distant CNS metastasis); and 3) survival. Although one might assume that the first two findings should result in an increase in survival, this is not certain. Nonetheless, the prevention of CNS morbidity by itself would justify using one therapy over another.

The major treatment strategies with which to attain local control of single metastasis are WBRT, resection, focused radiation (that is, RS or brachytherapy), or a combination thereof. For prevention of distant CNS metastasis, WBRT is the primary modality used. Chemotherapy could be considered an alternative for distant control, but Class I or II data of its effectiveness are lacking at the present. All three methods of treatment (WBRT, resection, and RS) are thought to affect survival. We classified the selected articles according to the combinations of therapeutic modalities studied, as shown in Table 2. A direct comparison of results was limited by the end points used in the various studies and will be discussed later. Unless explicitly stated otherwise, we have assumed that survival is measured from the date of treatment.

\section{RESULTS}

\section{Prognosis of Patients Treated Using WBRT Alone}

Median survival time for patients treated using WBRT alone ranged from 3.5 to 8.2 months. Among the articles selected, all three classes of evidence relating to this treatment strategy were represented. We found data from six studies ${ }^{18,39,40,47-49,67}$ with Class I evidence which allowed us to consider survival rates for patients treated with WBRT (Table 3). 
TABLE 2

Combinations of therapeutic modalities in the 26 reviewed studies*

\begin{tabular}{|c|c|c|c|c|}
\hline \multirow{2}{*}{$\begin{array}{l}\text { Type of } \\
\text { Evidence }\end{array}$} & \multicolumn{4}{|c|}{ Treatment } \\
\hline & Surgery & RS & WBRT & No WBRT \\
\hline \multirow[t]{4}{*}{ Class I } & Yes & Yes & & \\
\hline & Yes & No & $39,47,48,67$ & \\
\hline & No & Yes & & 47 \\
\hline & No & No & $18,39,40,48,49,67$ & \\
\hline \multirow[t]{4}{*}{ Class II } & Yes & Yes & & \\
\hline & Yes & No & 3,56 & 3 \\
\hline & No & Yes & & \\
\hline & No & No & 56 & \\
\hline \multirow[t]{4}{*}{ Class III } & Yes & Yes & & 54 \\
\hline & Yes & No & $\begin{array}{c}6,12,14,15,36,38 \\
44,46,54,55,59 \\
60,68,72,76\end{array}$ & $\begin{array}{l}13,16,23,31, \\
59,60,68, \\
73,76\end{array}$ \\
\hline & No & Yes & $4,6,23$ & $34 \dagger$ \\
\hline & No & No & $14,36,38,44,46,55$ & \\
\hline
\end{tabular}

* Numbers indicate references.

$\dagger$ Brachytherapy is used in this study.

In studies by Mintz and colleagues ${ }^{39}$ Patchell and associates, ${ }^{47}$ and Vecht, et al., ${ }^{67}$ patients with single metastasis to the brain treated using WBRT alone were compared with those treated using resection followed by radiotherapy. Various types of tumors were represented in each series, but radiosensitive tumors were excluded from all. Eligibility criteria were similar among all three studies. In the study conducted by Mintz and colleagues, patients were treated with 30 Gy of WBRT in 10 fractions. Median survival was 6.28 months and death resulting from neurological $(27.9 \%)$ or combined neurological and systemic progression occurred in $62.8 \%$ of patients studied. In the study by Patchell and associates patients were treated using 36 Gy of WBRT in 12 fractions. Median survival in these patients was only 15 weeks. The high percentage of patients with non-small cell lung cancer, a relatively less radiosensitive tumor type, may account for the poorer survival rate in this study. In the Vecht, et al., investigation, patients were treated with $40 \mathrm{~Gy}$ administered in daily 2-Gy fractions. Patients with stable extracranial disease had median survival rates of 7 months. ${ }^{67}$

Phillips, et al., ${ }^{49}$ reported on a randomized study of patients with presumed brain metastasis (no other sites of active disease) treated with either $37.5 \mathrm{~Gy}$ administered in 15 2.5-Gy fractions to the whole brain or $37.5 \mathrm{~Gy}$ with the radiation sensitizer $\mathrm{BrdU} 0.8 \mathrm{~g} / \mathrm{meter}^{2} /$ day for 3 days. Although the overall median survival rate for patients with single and multiple metastases was not significantly different between these two treatment groups (6.12 months for WBRT alone compared with 4.3 months for radiotherapy plus BrdU), the survival rate of patients with single metastasis was 6.98 months. It was not possible to extract data on median survival for patients with single metastases from each treatment arm.

Murray and colleagues ${ }^{40}$ reported on RTOG 9104, a randomized phase III trial of accelerated hyperfractionation in which a treatment strategy of 1.6-Gy fractions twice daily of WBRT administered initially to a total dose of $54.4 \mathrm{~Gy}$ was compared with standard radiotherapy of 30 Gy in 10 fractions. Patients with uncontrolled systemic
TABLE 3

Prognosis of patients with single brain metastasis treated with WBRT*

\begin{tabular}{lcll}
\hline \hline \multicolumn{1}{c}{ Authors \& Year } & $\begin{array}{c}\text { No. of } \\
\text { Patients }\end{array}$ & $\begin{array}{l}\text { Radiation } \\
\text { Dose }(\mathrm{Gy})\end{array}$ & $\begin{array}{c}\text { Survival } \\
\text { (mos) }\end{array}$ \\
\hline Patchell, et al., 1990 & 23 & 36 & 3.75 \\
Epstein, et al., 1991 & 30 & $32 / 48 \mathrm{AH}$ & 4.9 \\
& 53 & $32 / 54.4 \mathrm{AH}$ & 5.4 \\
& 44 & $32 / 64 \mathrm{AH}$ & 7.2 \\
Vecht, et al., 1993 & 26 & $32 / 70.4 \mathrm{AH}$ & 8.2 \\
Phillips, et al., 1995 & 31 & 40 & 7 \\
Mintz, et al., 1996 & 30 & 37.5 & 6.98 \\
Murray, et al., 1997 & 43 & 30 & 6.28 \\
& 60 & $3.2 / 54.4 \mathrm{AH}^{*}$ & 4.5 \\
& 60 & 30 & 5.3 \\
\hline
\end{tabular}

$* \mathrm{AH}=$ accelerated hyperfractionation.

disease were ineligible to participate in the study. Overall median survival including patients with single and multiple metastases in both treatment arms was 4.5 months. Sixty patients with single metastasis were accrued to each treatment arm, and the rate of survival in patients in the standard radiotherapy arm was 5.3 months compared with 4.5 months in those in the accelerated hyperfractionation arm.

In a phase I/II trial, RTOG 85-28, Epstein, et al., ${ }^{18}$ noted improved survival for patients with single brain metastasis treated with accelerated hyperfractionation (1.6 Gy administered twice daily to $32 \mathrm{~Gy}$, with groups determined by boost escalation to total doses of 48, 54.4, 64, and $70.4 \mathrm{~Gy}$ ). Median survival rates were 4.9 months for patients treated with $48 \mathrm{~Gy}, 5.4$ months with $54.4 \mathrm{~Gy}, 7.2$ months with $64 \mathrm{~Gy}$, and 8.2 months with $70.4 \mathrm{~Gy}$.

\section{Patient Outcome and Resection Combined With WBRT Compared With WBRT Alone}

Results from two of three randomized controlled trials demonstrated benefit from resection in patients with single brain metastasis. In these studies Class I evidence demonstrates the effect of resection plus WBRT compared with WBRT alone and permits analysis of the role of surgery.

Patchell and associates ${ }^{48}$ performed a prospective randomized trial of single brain metastasis treatment using either WBRT alone or resection plus WBRT. Patients older than 18 years of age with a KPS score over 70 and a single metastasis were eligible to participate in the study. Other exclusion criteria included having lesions not resectable, leptomeningeal disease, previous cranial radiation, a need for emergency surgery, small cell lung cancer, lymphoma, leukemia, germ cell tumors, or multiple myeloma. All patients underwent postoperative CT to assess the effects of gross total resection of the tumor, and all patients received 36 Gy of WBRT. Baseline characteristics of the patients in each group were comparable. Median survival time was longer in the combined therapy group (40 weeks) compared with that in the WBRT group (15 weeks). In addition, a lower rate of recurrence at the initial site of metastasis and prolongation of time to recurrence (median 59 weeks compared with 21 weeks, respectively, $\mathrm{p}<0.001)$ was noted in the resection group. In 
analyzing survival as a function of neurological death, we found that patients in the resection group compared favorably (62 weeks compared with 26 weeks). The authors concluded that the overall improvement in survival outcome in the resection group was a result of a reduction in deaths from neurological disease.

Vecht, et al., ${ }^{67}$ reported a randomized controlled prospective study of 63 patients who were treated with either resection plus radiotherapy compared with radiotherapy alone. Radiotherapy was administered two times per day in 2-Gy fractions to a total of $40 \mathrm{~Gy}$. Patients were stratified according to type of cancer (lung versus nonlung) and status of extracranial disease. Eligible patients were older than 18 years of age and had a histologically verified malignancy and a single lesion demonstrated on cranial CT. Patients with small cell lung cancer, lymphoma, leptomeningeal disease, or more than one brain lesion were excluded. Follow-up data on all 63 patients were recorded. Diagnosis was correct in all patients who underwent surgery. The median survival rate in patients with stable systemic disease was 12 months compared with 7 months for those with progressive systemic disease. Patients were functionally independent longer in the resection group (9 compared with 4 months, $\mathrm{p}<0.06$ ). In comparing patients having progressive systemic disease, median survival of those in the resection group and the radiotherapy group was equivalent (5 months). Intracranial cause of death as determined clinically was also the same in both groups.

Mintz and associates ${ }^{39}$ performed a prospective randomized controlled trial in which patients who had a single brain metastasis were treated using either WBRT alone or surgery plus WBRT. Radiotherapy consisted of a total of 30 Gy to the whole brain delivered in 10 fractions. Gross total resection was judged by results of CT performed within the first week postsurgery. Exclusion criteria consisted of a KPS score less than 50, leukemia, lymphoma, small cell lung cancer, skin cancer other than melanoma, meningeal carcinomatosis, previous radiotherapy treatment, comorbid conditions precluding adequate follow-up review, brainstem or basal ganglion lesion, or more than one metastasis. Survival was calculated from the time of randomization, and cause of death was classified as either neurological or systemic. The locations of the brain metastases were considered to be relatively comparable, but details of eloquent compared with noneloquent locations were not included. We found no difference in median survival rate between the two treatment groups (resection plus WBRT 5.6 months compared with WBRT alone 6.3 months, $\mathrm{p}<0.24$ ). There were no significant differences in morbidities or causes of death. Neurological causes accounted for $14.6 \%$ of deaths in the resection treatment arm and $27.9 \%$ in the WBRT only arm. In the resection and WBRT only groups, systemic causes of death accounted for $46.3 \%$ and $34.9 \%$, respectively. Quality of life outcomes were assessed using the Spitzer quality of life index which assesses five domains: activity, daily life, health, support, and outlook. There was no significant difference in quality of life between the groups by using this measure for 6 months of follow up. In this intention-to-treat analysis, there were protocol violations in both groups. In the resection group four patients died before WBRT, one refused WBRT, two withdrew from the study before surgery but after having undergone one treatment of WBRT, one had a glioblastoma multiforme and did not undergo WBRT, and 38 of 40 underwent gross total resection. In the WBRT alone group, one patient died several days after randomization and did not receive radiation treatment and 10 patients experienced surgical intervention. Only $2.3 \%$ of the patients in the resection group were misdiagnosed, and all nine of the patients who switched from the WBRT group to the resection group were accurately diagnosed.

Two articles with Class II evidence have comments on the value of surgery and radiation therapy.,56 Armstrong, et al., ${ }^{3}$ retrospectively reviewed data on 143 patients who were treated using resection between 1974 and 1989. Thirty-two patients who received no postoperative radiation were compared with 32 patients who received $39 \mathrm{~Gy}$ per 10 days). Statistically, radiotherapy had no effect on survival or brain failure rates, but did have some impact on local brain control.

\section{Patient Outcome and WBRT Combined With Surgery Compared With Surgery Alone}

In the only published randomized controlled trial selected for review, patients receiving radiation postoperatively had a lower rate of brain tumor recurrence. In the study by Patchell, et al., ${ }^{47}$ a prospective randomized multicenter controlled trial, patients who underwent surgery alone were compared with those who underwent surgery plus postoperative radiotherapy for the management of single brain metastasis. The enrollment criteria were similar to those noted in these authors' 1990 study (Table 4) ${ }^{48}$ Fortynine patients underwent postoperative radiotherapy and 46 patients received no radiation treatment but were subject to observation. Patients received 50.4 Gy (1.8 Gy in 28 fractions) over 5.5 weeks. Resections were judged to be complete with the aid of postoperative MR images. The primary end point in this trial "the recurrence of brain tumor" was noted in $18 \%$ of patients in the radiation group and $70 \%$ in the observation group. Patients in the radiotherapy group were less likely to die of neurological disease (14 compared with 44\%); however, there was no significant difference in overall survival rate between groups. Postoperative radiotherapy was associated with a lower incidence of recurrence at the primary site (14 compared with $37 \%$ ).

\section{Prognosis of Patients With Single Brain Metastasis Treated Using RS With or Without WBRT}

We found insufficient evidence to reach a conclusion about the prognosis of patients with single brain metastasis who underwent either RS and WBRT or RS alone. Among the articles selected, only those with Class III evidence allowed us to assess the role of RS in the treatment of single brain metastasis. Auchter and colleagues ${ }^{4}$ reported on 122 patients who were treated using a linear accelerator-based procedure. The selection criteria for patients in this retrospective analysis were similar to those in the study of Patchell, et al. ${ }^{48}$ Patients had to be older than 18 years of age and have a single surgically resectable brain metastasis of nonradiosensitive histology and a KPS score greater than 70 . The peripheral dose ranged from 10 to 27 Gy and the median dose was 17 Gy. Whole-brain radiation 
TABLE 4

Class I evidence of patients treated with WBRT with or without surgery*

\begin{tabular}{|c|c|c|c|c|c|c|c|}
\hline Authors \& Year & $\begin{array}{l}\text { No. of } \\
\text { Patients }\end{array}$ & $\begin{array}{l}\text { Radiation } \\
\text { Dose (Gy) }\end{array}$ & Surgery & $\begin{array}{c}\text { Overall } \\
\text { Survival } \\
\text { (mos) }\end{array}$ & $\begin{array}{l}\text { Neurolog- } \\
\text { ical Survi- } \\
\text { val (mos) }\end{array}$ & $\begin{array}{c}\text { Local } \\
\text { Control } \\
\text { Rate }(\%)\end{array}$ & $\begin{array}{c}\text { Distant } \\
\text { Control } \\
\text { Rate (\%) }\end{array}$ \\
\hline \multirow[t]{2}{*}{ Patchell, et al., 1990} & 25 & 36 & GTR & 9.3 & 14.5 & 80 & 92 \\
\hline & 23 & 36 & None & 3.75 & 6.1 & 48 & 100 \\
\hline \multirow[t]{2}{*}{ Vecht, et al., 1993} & 31 & 40 & GTR & 10 & & & \\
\hline & 32 & 40 & None & 4 & & & \\
\hline \multirow[t]{2}{*}{ Mintz, et al., 1996} & 41 & 30 & GTR & 5.6 & & & \\
\hline & 43 & 30 & None & 6.3 & & & \\
\hline
\end{tabular}

* GTR $=$ gross total resection .

therapy was applied in all but five patients who refused this modality, and the radiation dose ranged from 25 to 40 Gy with a median dose of $37.5 \mathrm{~Gy}$. The median follow-up review of patients was 123 weeks and the local control rate, which was defined as no progression in radiosurgical volume, was $86 \%$. The rate of intracranial recurrence outside of the radiosurgical volume was $22 \%$. The actuarial rate of survival from the time of radiosurgery was 56 weeks, and the 1-year and 2-year survival rates were 53\% and $30 \%$, respectively. Patients maintained a KPS score greater than 70 for 44 weeks. Survival analysis included the status of the primary disease and, thus, $25 \%$ of deaths could be attributed to CNS progression.

Flickinger, et al. ${ }^{23}$ reported on 116 patients who underwent RS alone (51 patients) and RS plus fractionated large-field radiotherapy (65 patients). Forty-five patients had received no benefit from previous radiotherapy, whereas 71 patients had received no previous radiotherapy. Median follow up after radiotherapy of the entire cohort was 7 months. Minimum radiosurgery dosages varied between 8 Gy and 30 Gy with a mean of 17.9 Gy. Maximum radiosurgical dosages varied between $16 \mathrm{~Gy}$ and $66.7 \mathrm{~Gy}$, with a mean of $34.8 \mathrm{~Gy}$. The total dosage of fractionated radiotherapy varied between 20 Gy and 77 Gy, with a mean dose per fraction of $2.5 \mathrm{~Gy}$. The mean dose administered with RS was 33 Gy, with a range between 14 Gy and 55 Gy. Average tumor diameter varied between $3 \mathrm{~mm}$ and $36 \mathrm{~mm}$ with a mean of $18.7 \mathrm{~mm}$. Patients were older than 24 years of age and all but four cases were found to be nonradiosensitive histologically. For patients who were managed from the time of initial diagnosis, the median survival time was 14 months. Among the entire cohort, the local control rate was $85 \%$ with tumor progression in $15 \%$. The 2-year actuarial tumor control rate was $67 \pm 8 \%$. According to results of multivariate analysis, local tumor control was better in patients who underwent RS plus fractionated radiotherapy $(p=0.0111)$. In a subset analysis of patients who were treated initially by using RS alone compared with those treated using RS plus radiotherapy, local control was better in those treated with the combination therapy $(\mathrm{p}=$ 0.008 ). One patient had symptomatic, pathologically documented radiation necrosis, and four patients developed symptomatic edema requiring reinstitution of steroid therapy.

Bindal and associates ${ }^{6}$ reported on two series of patients: 31 treated using RS and 62 treated using surgery and WBRT. (Although both groups had comparable per- centages of patients treated using WBRT, circumstances which led to the addition of WBRT in the RS group could bias the results.) Groups were retrospectively matched according to systemic disease status, histology, pretreatment KPS score, time to brain metastasis, number of metastases, and patient age and sex. In patients in the RS group, the median lesion size was $1.96 \mathrm{~cm}^{3}$ (range $0.41-$ $8.25 \mathrm{~cm}^{3}$ ), and the median dose applied to the isocenter was 20 Gy (range 12-22 Gy). In all cases, only one isocenter was used. In the RS group, 22 of 31 patients received WBRT and 16 of these 22 received pre-RS radiotherapy. (It is unclear how many of these 16 patients received little or no benefit from WBRT, a poor prognostic variable for successful subsequent RS.) In patients in the surgery group, 41 of 62 also received WBRT. The median survival of patients in the surgery group was 16.4 months compared with 7.5 months for those in the RS group. It is impossible to isolate the patients in the RS group who were treated at the time of initial diagnosis from those who were treated with RS after a recurrence or a progression, and directly to compare them with those who were treated surgically (another source of bias for the same reason noted earlier in the discussion of the study by Flickinger, et al. ${ }^{23}$ ). Neurological causes accounted for $50 \%$ of deaths in the RS group compared with 19\% in the surgery group. Recurrence was local in $8.1 \%$ and distant in $21 \%$ of patients in the surgery group compared with $38.7 \%$ and $9.7 \%$, respectively, in patients in the RS group. In patients in the RS group complications of symptomatic radionecrosis occurred in $12.9 \%$ and intratumoral hemorrhage in $9.7 \%$ (leading to death in one patient). In patients in the surgery group complications included two postoperative hematomas, which required no reoperation, and one instance of wound infection, which was treated with antibiotics.

\section{Prognosis of Patients With Single Brain Metastasis Treated Using Interstitial Implant Radiotherapy}

We found insufficient evidence to reach a conclusion regarding the prognosis of patients with single brain metastasis treated using interstitial implant radiotherapy.

Kreth, et al., ${ }^{34}$ conducted a Class III retrospective review in which was studied the survival of patients following stereotactic biopsy and subsequent treatment with temporary low-activity IRS calculated to administer a radiation dose (range 60-100 Gy) to the outer diameter of the contrast-enhancing lesion. The following four groups 
were treated: 38 patients ( 35 with solitary and three with multiple brain metastases) were treated using combined IRS and WBRT (40 Gy administered in 2 Gy fractions every day for 5 days), 49 were treated using WBRT alone (40 Gy administered in 2 Gy fractions every day for 5 days), 22 were treated using IRS alone (60 Gy), and 21 were treated using IRS for recurrent disease. Although subgroup analysis is not provided in the report, the patients who underwent combined treatment had a median survival of 17 months, compared with 12 and 7.7 months for IRS alone and WBRT, respectively. These data compare favorably with those in the literature, but the absence of a cohort analysis and a clear separation of data between patients with solitary metastasis and those with multiple metastases, as well as the inability to relate systemic disease status for individual patients do not allow for valid comparison to other Class III studies in the literature.

\section{DISCUSSION}

\section{Prognosis of Patients With Single Brain Metastasis Treated Using WBRT Alone}

The survival of patients treated using WBRT in the control arms of various randomized trials ranged from 3.75 to 8.2 months (Table 3). The rate of local control of the tumor was not evident from these studies alone. One must remain cautious while reviewing studies that report survival data on patients with single metastases and stable systemic disease which have been extracted from a larger patient series, including patients with multiple metastases or patients with advanced systemic disease. It can be difficult to determine if certain factors have introduced bias into the analysis of the group of patients with single metastasis. For example, it is common to require that patients entered into randomized trials have an estimated survival of at least 3 months and a minimum KPS. Thus, resulting data in such a trial do not represent the entire patient population with single brain metastases, but represent a population with better than average prognosis.

\section{Patient Outcome and Surgery Combined With WBRT Compared With WBRT Alone}

Data from two of three randomized trials that address the question of whether patient outcome is improved in patients treated using surgery combined with WBRT compared with WBRT alone indicated that surgery provided significant benefit. There are several possible explanations for the discrepancy in results. Mintz, et al., ${ }^{39}$ assert that improved survival outcomes after surgery in the study conducted by Patchell and associates ${ }^{48}$ may reflect a referral bias because the patients were accrued after referral to a neurosurgical service, whereas the patients in the studies by Vecht and colleagues ${ }^{67}$ and Mintz, et al. ${ }^{39}$ were referred by oncologists, neurologists, neurosurgeons, and radiation oncologists. They further assert that survival in the Patchell nonsurgical group (3.75 months) was unusually low and may have resulted from the inclusion of a higher percentage of patients with non-small cell lung cancer (77\%), a relatively radioresistant tumor type. On the other hand, the advantage of surgery may be lost in patients with advanced systemic disease. In the Mintz trial $45 \%$ of patients, compared with $37.5 \%$ in the Patchell and $31.7 \%$ in the Vecht trial, had systemic metastases that may have limited the positive effects of surgery.

Another major difference between the Mintz study and the Patchell and Vecht studies was the administered dose of WBRT. In the Vecht study patients were treated to a total dose of $40 \mathrm{~Gy}$ was applied to patients. (Smalley, et al. ${ }^{60}$ demonstrated that dosages greater than 39 Gy compared favorably with lower doses). In the Patchell study patients received $36 \mathrm{~Gy}$, whereas $30 \mathrm{~Gy}$ was administered to patients in the Mintz trial. An interaction between surgery and the dose of WBRT cannot be ruled out with the existing data.

Note that all three studies with Class I evidence were of relatively small sample sizes. Although the additional patient survival time attributed to surgery in both the Patchell and Vecht studies cannot be considered to be definitively proven, the preponderance of Class I evidence indicates that in patients who meet the eligibility criteria in these studies and who receive at least 36 Gy of WBRT, surgical excision of the metastasis can more than double survival time.

\section{Patient Outcome and WBRT Combined With Surgery Compared With Surgery Alone}

Data from the study by Patchell, et al., ${ }^{47}$ demonstrates that the addition of WBRT to surgical excision improves the local control rate (an increase in survival from 43 to 48 weeks). In this study, however, a significant increase in survival was not demonstrated.

\section{Prognosis of Patients With Single Brain Metastases Treated Using RS With or Without WBRT}

In contrast to surgical excision, stereotactic RS has not been subjected to a randomized comparison with either WBRT alone or surgery with or without WBRT. As evidenced by the studies reviewed for this report, it is often difficult to isolate from case series patients comparable with those in surgical trials. Therefore, inferences about the comparability of radiosurgery and surgical excision are subject to bias uncontrolled by proper research procedures. For example, in the study by Flickinger and colleagues, ${ }^{23}$ it is not possible to separate outcomes of patients who underwent RS as their primary treatment from those who were treated for recurrence. In addition, the radiosurgical studies use stable disease-partial and complete responses combined (local control rate)-as the measure of technical success. Authors of surgery trials consider residual tumor at the surgical site to be technical failure. A $20 \%$ increase in the size of the tumor would be considered as stable and therefore a success in a radiosurgical trial-an inconceivable interpretation in a surgery trial. Whether these differences in the measurement of outcome reflect a difference in the biological behavior of the treated tumor is unknown, because the necessary studies have not been done. As a result of these limitations, it is impossible to conclude that RS is comparable with resection in its effect on patient survival or quality of life.

\section{CONCLUSIONS}

A distinction must be made between evidence-based practice parameters and algorithms or other consensus- 
derived recommendations for clinical practice. The former defines the state of scientific knowledge supporting clinical treatment of a given condition. The latter combines that scientific knowledge with collected experience, interpreted in the context of the individual patient to suggest the most appropriate course of action. Evidence-based practice parameters, by their very nature, will always have limitations when applied to individual patient care decisions, but should form the base from which the practitioner interprets the individual situation and recommends action.

What, then, can be said about the optimal therapy for an adult patient with a single brain metastasis from a non-CNS malignancy? There is insufficient information to establish any recommendations as standards. We can, however, propose a guideline: resection accompanied by WBRT promotes the best survival rate. The available Class I evidence indicates that this guideline applies to patients whose KPS score exceeds 50 (70 in the studies with significant treatment effects) and who have no certain radiosensitive tumors (such as small cell lung, germ cell, myeloma, lymphoma, and leukemia). These criteria are compatible with an average survival of 3.75 to 6.3 months in the control population. In this population, the predominance of Class I evidence suggests that resection of the single metastasis accompanied by WBRT provides the best possibility of survival. Because one trial (Mintz, et al.) does not support this conclusion and raises important questions about the dose of radiotherapy, the pretreatment KPS score, and possible referral bias, we cannot establish a standard.

Class III evidence indicates that radiosurgery for lesions smaller than $2.5 \mathrm{~cm}$ accompanied by WBRT may provide an effective alternative to conventional resection plus WBRT. However, the impact on survival and quality of life in comparison to conventional surgery and WBRT is unknown. Other forms of focal therapy have not been sufficiently tested to allow a reasoned assessment of their role in the treatment of solitary brain metastasis.

\section{DISCLAIMER}

These practice parameters are provided as an educational service of the AANS, the AAN, and the ASTRO. These sponsoring organizations have not endorsed these guidelines. The guidelines are based on critical analysis of the available evidence in the medical literature. They are not intended to include all possible clinical scenarios in patients with a single brain metastasis. They do not address and are not intended to exclude alternative treatments. The authors representing the AANS, AAN, and ASTRO recognize that patient care decisions are the responsibility of the patients and the physician(s) caring for the patient and must be individualized based on all of the circumstances involved.

\section{References}

1. Alexander E III, Moriarty TM, Davis RB, et al: Stereotactic radiosurgery for the definitive, noninvasive treatment of brain metastases. J Natl Cancer Inst 87:34-40, 1995
2. Andrews RJ, Gluck DS, Konchinger RH: Surgical resection of brain metastases from lung cancer. Acta Neurochir 138: 382-389, 1996

3. Armstrong JG, Wronski M, Galicich J, et al: Postoperative radiation for lung cancer metastatic to the brain. J Clin Oncol 12: 2234-2344, 1994

4. Auchter RM, Lamond JP, Alexander E, et al: A multiinstitutional outcome and prognostic factor analysis of radiosurgery for resectable single brain metastasis. Int J Radiat Oncol Biol Phys 35:27-35, 1996

5. Badalament RA, Gluck RW, Wong GY, et al: Surgical treatment of brain metastases from renal cell carcinoma. Urology 36:112-117, 1990

6. Bindal AK, Bindal RK, Hess KR, et al: Surgery versus radiosurgery in the treatment of brain metastases. J Neurosurg 84: 748-754, 1996

7. Bindal RK, Sawaya R, Leavens ME, et al: Surgical treatment of multiple brain metastases. J Neurosurg 79:210-216, 1993

8. Brega K, Robinson WA, Winston K, et al: Surgical treatment of brain metastases in malignant melanoma. Cancer 66: 2105-2110, 1990

9. Burt M, Wronski M, Arbit E, et al: Resection of brain metastases from non-small cell lung carcinoma. Results of therapy. J Thorac Cardiovasc Surg 103:399-411, 1992

10. Byrne TN, Cascino TL, Posner JB: Brain metastases from melanoma. J Neurooncol 1:313-317, 1983

11. Coffey RJ, Flickinger JC, Lunsford LD, et al: Solitary brain metastases: radiosurgery in lieu of microsurgery in 32 patients. Acta Neurosurg Suppl 52:90-92, 1991

12. DeAngelis LM, Mandell LR, Thaler HT, et al: The role of postoperative radiation therapy after resection of single brain metastases. Neurosurgery 24:798-805, 1989

13. Decker DA, Decker VL, Herskovic A, et al: Brain metastases in patients with renal cell carcinoma: prognosis and treatment. J Clin Oncol 2:169-173, 1984

14. Demange L, Tack L, Morell M, et al: Single brain metastasis of nonsmall cell lung carcinoma: study of survival among 54 patients. Br J Neurosurg 3:81-88, 1989

15. Dosoretz DE, Blitzer PH, Russell AH, et al: Management of solitary metastases to the brain: the role of elective brain irradiation following complete surgical resection. Int J Radiat Oncol Biol Phys 6:1727-1730, 1980

16. Eddy DM: Designing a practice policy: standards, guidelines and options. JAMA 263:3077-3084, 1990

17. Engenhart R, Kimmig BN, Hover KH, et al: Long-term followup for brain metastases treated by percutaneous stereotactic single high-dose irradiation. Cancer 71:1353-1361, 1993

18. Epstein BE, Scott CB, Sause WT, et al: Improved survival duration in patients with unresected solitary brain metastases using accelerated hyperfractionated radiation therapy at total doses of 54.4 gray and greater. Results of Radiation Therapy Oncology Group 85-28. Cancer 71:1362-1367, 1993

19. Farnell GF, Buckner JC, Cascino TL, et al: Brain metastases from colorectal carcinoma. Cancer 78:711-716, 1996

20. Fell DA, Leavens ME, McBride CM: Surgical versus nonsurgical management of metastatic melanoma of the brain. Neurosurgery $7: 238-242,1980$

21. Fernandez-Vicioso E, Suh JH, Kupelian PA, et al: Analysis of prognostic factors for patients with single brain metastases treated with stereotactic radiosurgery. Radiat Oncol Invest 5:31-37, 1997

22. Ferrara M, Bizzozzero L, Talamonti G, et al: Surgical treatment of 100 single brain metastases. Analysis of the results. J Neurosurg Sci 34:303-308, 1990

23. Flickinger JC, Konziolka D, Lunsford LD, et al: A multiinstitutional experience with stereotactic radiosurgery for solitary brain metastasis. Int J Radiat Oncol Biol Phys 28:797-802, 1994 
24. Galicich JH, Sundaresan N, Arbit E, et al: Surgical treatment of single brain metastases: factors associated with survival. Cancer 45:381-386, 1980

25. Hafstrom L, Jonsson PE, Stromblad G: Intracranial metastases of malignant melanoma treated by surgery. Cancer 46: 2088-2090, 1980

26. Hagen NA, Cirrincione C, Thaler HT, et al: The role of radiation therapy following resection of single brain metastases from melanoma. Neurology 40:158-160, 1990

27. Hankins JR, Miller JE, Salcman M, et al: Surgical management of lung cancer with solitary cerebral metastasis. Ann Thorac Surg 46:24-28, 1988

28. Hazuka MB, Burleson WD, Stroud DN, et al: Multiple brain metastases are associated with poor survival in patients treated with surgery and radiosurgery. J Clin Oncol 11:369-373, 1993

29. Isokangas OP, Muhonen T, Kajanti M, et al: Radiation therapy of intracranial malignant melanoma. Radiother Oncol 38: 139-144, 1996

30. Joseph J, Adler JR, Cox RS, et al: Linear accelerator-based radiosurgery for brain metastases: the influence of number of lesions on survival. J Clin Oncol 14:1085-1092, 1996

31. Katz $\mathrm{H}$ : The relative effectiveness of radiation therapy, corticosteroids, and surgery in the management of melanoma metastatic to the central nervous system. Int J Radiat Oncol Biol Phys 7:897-906, 1981

32. Kelly PJ, Kali BA, Goerss SJ: Results of computed tomography-based computer assisted resection of metastatic intracranial tumors. Neurosurgery 23:7-17, 1988

33. Kochhar R, Frytak S, Shaw EG: Survival of patients with extensive small-cell lung cancer who have only brain metastases at initial diagnosis. Am J Oncol 20:125-127, 1997

34. Kreth FW, Warnke PC, Ostertag CB: Interstitial implant radiosurgery for cerebral metastases. Acta Neurochir Suppl 58: $112-114,1993$

35. Leavens ME, Moser RP, Obbens EA, et al: Surgical treatment of metastatic brain tumors. Bull Cancer 38:39-44, 1986

36. Madajewicz S, Karakousis C, West CR, et al: Malignant melanoma brain metastases. Review of Roswell Park Memorial Institute experience. Cancer 53:2550-2552, 1984

37. Magilligan DJ Jr, Duvernoy C, Malik G, et al: Surgical approach to lung cancer with solitary cerebral metastases: twentyfive years' experience. Ann Thor Surg 42:360-364, 1986

38. Mandell L, Hilaris B, Sullivan M, et al: The treatment of single brain metastases from non-oat cell lung carcinoma. Surgery and radiation versus radiation therapy alone. Cancer 58:641-649, 1986

39. Mintz AH, Kestle J, Rathbone MP, et al: A randomized trial to assess the efficacy of surgery in addition to radiotherapy in patients with single brain metastasis. Cancer 78:1470-1476, 1996

40. Murray KJ, Scott C, Greenberg HM, et al: A randomized phase III study of accelerated hyperfractionation versus standard in patients with unresected brain metastases: a report of the Radiation Therapy Oncology Group (RTOG) 9104. Int J Radiat Oncol Biol Phys 39:571-574, 1997

41. Mussi A, Pistolesi M, Lucchi M, et al: Resection of single brain metastasis in non-small cell lung cancer. J Thorac Cardiovasc Surg 12:146-153, 1996

42. Nakagawa H, Miyawaka Y, Fijita T, et al: Surgical treatment of brain metastases of lung cancer: retrospective analysis of 89 cases. J Neurol Neurosurg Psychiatry 57:950-956, 1994

43. Noordijk EM, Vecht CJ, Haaxa-Reiche H, et al: The choice of treatment of single brain metastasis should be based on extracranial tumor activity and age. Int J Radiat Oncol Biol Phys 29:711-717, 1994

44. Nussbaum ES, Djalilian HR, Cho KH, et al: Brain metastases: histology, multiplicity, surgery and survival. Cancer 78: 1781-1788, 1996
45. Oredsson S, Ingvar C, Stromblad LG, et al: Palliative surgery for brain metastases of malignant melanoma. Eur J Surg Oncol 16:451-456, 1990

46. Patchell RA, Cirrincione C, Thaler HT, et al: Single brain metastases: surgery plus radiation or radiation alone. Neurology 36:447-453, 1986

47. Patchell RA, Tibbs PA, Regine WF, et al: Postoperative radiotherapy in the treatment of single metastasis to the brain: a randomized trial. JAMA 280:1-7, 1998

48. Patchell RA, Tibbs PA, Walsh JW, et al: A randomized trial of surgery in the treatment of single metastasis to the brain. $\mathbf{N}$ Engl J Med 322:494-500, 1990

49. Phillips TL, Scott CB, Leibel SA, et al: Results of a randomized comparison of radiotherapy and bromodeoxyuridine with radiotherapy alone for brain metastases: report of RTOG trial 8905. Int J Radiat Oncol Biol Phys 33:339-348, 1995

50. Posner JB: Management of central nervous system metastases. Semin Oncol 4:81-91, 1977

51. Posner JB, Chernick NL: Intracranial metastases from systemic cancer. Adv Neurol 19:579-591, 1978

52. Prados M, Leibel S, Barnett CM, et al: Interstitial brachytherapy for metastatic brain tumors. Cancer 63:657-660, 1989

53. Read RC, Boop WC, Yoder G, et al: Management of nonsmall cell lung carcinoma with solitary brain metastasis. J Thorac Cardiovasc Surg 98:884-890, 1989

54. Salvati M, Cervoni L, Defini R: Solitary brain metastasis from oat-cell lung cancer: clinical and prognostic features. Neurosurg Rev 19:221-225, 1996

55. Sampson JH, Carter JH Jr, Friedman AH, et al: Demographics, prognosis, and therapy in 702 patients with brain metastases from malignant melanoma. J Neurosurg 88:11-20, 1998

56. Sause WT, Crowley JH, Morantz R, et al: Solitary brain metastasis: results of an RTOG/SWOG protocol evaluation surgery + RT versus RT alone. Am J Clin Oncol 13:427-452, 1990

57. Sause WT, Scott CB, Krisch R, et al: Phase I/II trial of accelerated fractionation in brain metastases RTOG 85-28. Int J Radiat Oncol Biol Phys 26:653-657, 1993

58. Shirato H, Takamura A, Tomita M, et al: Stereotactic irradiation without whole-brain irradiation for single brain metastasis. Int J Radiat Oncol Biol Phys 37:385-391, 1997

59. Skibber MJ, Soong SJ, Austin L, et al: Cranial irradiation after surgical excision of brain metastases in melanoma patients. Ann Surg Oncol 3:118-123, 1996

60. Smalley SS, Laws ER Jr, O'Fallon JR, et al: Resection for solitary brain metastasis. Role of adjuvant radiation and prognostic variables in 229 patients. J Neurosurg 77:531-540, 1992

61. Smalley SS, Schray MF, Laws ER Jr, et al: Adjuvant radiation therapy after surgical resection of solitary brain metastasis: association with pattern of failure and survival. Int J Radiat Oncol Biol Phys 13:1611-1616, 1987

62. Sperduto PW, Hall WA: Radiosurgery, cost-effectiveness, gold standards, the scientific method, cavalier cowboys, and the cost of hope. Int J Radiat Oncol Biol Phys 36:511-512, 1996

63. Stevens G, Firth I, Coates A: Cerebral metastases from malignant melanoma. Radiother Oncol 23:185-191, 1992

64. Sturm V, Kimmig B, Engenhardt R, et al: Radiosurgical treatment of cerebral metastases. Method, indications and results. Stereotact Funct Neurosurg 5:717-20, 1991

65. Sundaresan N, Galicich JH: Surgical treatment of brain metastases. Clinical and computerized tomography evaluation of the results of treatment. Cancer 55:1382-1388, 1985

66. Ueki K, Matsutani M, Nakamura O, et al: Comparison of whole-brain radiation therapy and locally limited radiation therapy in the treatment of solitary brain metastases from non-small cell lung cancer. Neurol Med Chir 36:364-369, 1996

67. Vecht CJ, Haaxma-Rieche H, Noordijk EM, et al: Treatment of single brain metastasis: radiotherapy alone versus combined with neurosurgery? Ann Neurol 33:583-590, 1993 


\section{Practice parameters for single brain metastasis}

68. Weber F, Riedel A, Koning W, et al: The role of adjuvant radiation and multiple resection within the surgical management of brain metastases. Neurosurg Rev 19:23-32, 1996

69. White KT, Fleming TR, Laws ER Jr: Single metastases to the brain. Surgical treatment in 122 consecutive patients. Mayo Clin Proc 56:424-428, 1981

70. Winston KR, Walsh JW, Fischer EG: Results of operative treatment of intracranial metastatic tumors. Cancer 45:2639-2645, 1980

71. Wronski M, Arbit E, Burt M, et al: Survival after surgical treatment of brain metastases from lung cancer: a follow-up study of 231 patients between 1976 and 1991. J Neurosurg 83: 605-616, 1995

72. Wronski M, Arbit E, McCormick B: Surgical treatment of 70 patients with brain metastases from breast carcinoma. Cancer 80:1746-1754, 1997

73. Wronski M, Maor MH, Davis BJ, et al: External radiation of brain metastases from renal carcinoma: a retrospective study of
119 patients from the M.D. Anderson Cancer Center. Int J Radiat Oncol Biol Phys 37:753-759, 1997

74. Yardeni D, Reichenthal E, Zucker G, et al: Neurosurgical management of single brain metastasis. Surg Neurol 21:277-284, 1984

75. Ziegler CJ, Cooper JS: Brain metastases from malignant melanoma: conventional vs. high-dose-per-fraction radiotherapy. Int J Radiat Oncol Biol Phys 12:1839-1842, 1986

76. Zimm S, Wampler GL, Stablein D, et al: Intracerebral metastases in solid-tumor patients: natural history and results of treatment. Cancer 48:384-394, 1981

Manuscript received May 17, 2000.

Accepted in final form November 17, 2000.

Address reprint requests to: Jack P. Rock, M.D., Department of Neurosurgery, Henry Ford Hospital, 2799 West Grand Boulevard, Detroit, Michigan 48202. 